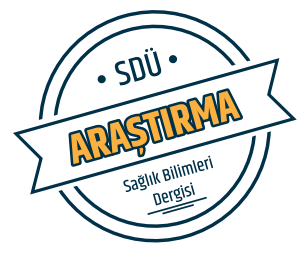

Sdü Sağlık Bilimleri Dergisi / Cilt 10 Sayı 1 / 2019

\title{
Menopoz Dönemine Yönelik Uygulanan Eğitim Programının Kadınların Menopoza Yönelik Tutumlarına Etkisi
}

\section{The Effect of Menopausal Training Program on Women's Attitudes of Menopause}

\author{
İlknur Münevver Gönenç ${ }^{1}$, Gülten Koç ${ }^{2}$ \\ ${ }^{1}$ Ankara Üniversitesi Hemşirelik Fakültesi, Ankara, Türkiye. \\ ${ }^{2}$ Hacettepe Üniversitesi Hemşirelik Fakültesi, Ankara, Türkiye.
}

\section{Özet}

Amaç: Araştırma menopoz dönemine yönelik uygulanan eğitim programının kadınların menopoza yönelik tutumlarına etkisini belirlemek amacı ile yapıldı.

Materyal-Metot: Araştırma ön test test-son test modeline dayalı yarı deneysel bir çalışma olarak yapıldı. Araştırma 23.11.2017-23.05.2018 tarihleri arasında 62 kadınla yürütüldü. Araştırmanın verileri araştırmacılar tarafindan geliştirilen Tanıtıcı Bilgiler Formu ve Menopoza İlişkin Tutum Ölçeği kullanılarak toplandı. Beş hafta boyunca kadınlara menopoza yönelik eğitim verildi. Kadınların menopoza yönelik tutumları eğitim öncesinde ve eğitimden iki ay sonra değerlendirildi.

Bulgular: Kadınların eğitim öncesi Menopoza İlişkin Tutum Ölçeği puan ortalaması $39,87+12,1$, eğitim sonras1 $52,32 \pm 10,33$ olduğu ve puan ortalamaları arasındaki farkın istatistiksel olarak önemli olduğu belirlendi $(p<0,001)$. Eğitim öncesinde menopoza yönelik olumlu tutuma sahip olan kadınların oranı $\% 51,6$, eğitim sonrasında $\% 85,5$ 'di ve iki ölçüm arasındaki farkın istatistiksel açıdan önemli olduğu saptandi $(p<0,001)$.

Sonuç: $\mathrm{Bu}$ araştırma menopoza yönelik verilen planlı sağlık eğitiminin, kadınların tutumlarını olumlu yönde geliştirdiğini ortaya koymuştur. Çalışma sonuçlarına göre menopozal dönemdeki kadınlara kapalı grup olarak düzenlenen planlı sağlık eğitimin sunulması ve bu eğitimin sağlık hizmetlerine entegre edilmesi önerilmiştir.

Anahtar kelimeler: Menopoz, Sağlık Eğitimi, Tutum, Kadın Sağlığı.

\begin{abstract}
Objective: The aim of the study was to determine the effect of the training program on menopause on women's attitudes towards menopause.
\end{abstract}

Material-Method: The research was a semi-experimental study which was based on pretest-posttest model. The study was carried out with 62 women between 23.11.201723.05.2018. The research data was collected by using the Introductory Information Form which is developed by researchers and the Attitudes Towards Menopause Scale (ATMS). Women were given menopause training for five weeks. Women's attitudes towards menopause were assessed two months before and after the training.

Results: Women's mean scores of ATMS were $39.87+12.1$, after the education, the mean scores of ATMS were $52.32 \pm 10.33$, and the difference between mean scores was statistically significant $(p<0.001)$. The percentage of women who had a positive attitude towards menopause was $51.6 \%$ before the training and $85.5 \%$ after the training. The difference between the two measurements was statistically significant $(\mathrm{p}<0.001)$.

Conclusions: In this study, it was determined that planned health education about menopause improved the attitudes of women positively. According to the results of the study, it has been suggested to planned health education as closed group for women in the menopausal period and to integrate this education in health services.

Keywords: Menopause, Health Education, Attitude, Women's Health.

\section{Giriş}

Menopoz yaşamın doğal ve sağlıklı bir süreci olup, kadın yaşamının önemli evrelerinden biridir. Menopoz, overlerin aktivitesinin durmas1 nedeniyle 12 ay veya daha uzun süre menstruasyonun kalıcı olarak sonlanmasıdır $(1,2)$. Günümüzde yaşam süresinin uzaması ile birlikte menopoz döneminde geçirilen süre de artmaktadır. $\mathrm{Bu}$ dönemde kadınlar fizyolojik, mental, sosyal ve cinsel yönden birçok değişim yaşamaktadır (3). Menopoz döneminde hormonal değişikliklere bağlı olarak vazomotor semptomlar, gece terlemeleri, ateş basması, kas ve iskelet sistemi problemleri, kardiyovasküler sistem hastalıkları, memelerde ve üreme organlarında atrofi ortaya çıkabilmektedir (4). Bazı kadınlar yaşanan bu değişiklikleri doğal bir sürecin parçası ve olağan bir durum olarak algılayıp başetme becerisi geliştirirken, bazı kadınlar yaşam kalitelerini olumsuz etkileyecek ciddi problemler yaşayabilmektedir $(3,4)$. Menopoz, yalnızca biyolojik değil, aynı zamanda psiko-sosyal, duygusal, 
ekonomik ve kültürel faktörlerden etkilenen bir yaşam krizi olarak belirtilmektedir. Menopoz döneminde kadınlarda benzer fizyopatolojik süreçler yaşanmasına rağmen, farklı sorunlar ortaya çıkabilmektedir (5). Bu sorunların sayısı ve şiddeti kadının içinde yaşadığı kültüre, menopoz yaşına, menopoza giriş şekline, kadının toplumsal cinsiyet rollerine ve kadının bu döneme ait bilgi ve tutumuna göre değişmektedir (6). Kadınların menopoz dönemine yönelik tutumlarının olumsuz olması bu dönemin daha sıkıntılı bir süreç olarak geçmesine neden olmaktadır. Literatürde olumlu menopozal tutum içinde olan kadınların daha az menopozal semptom yaşadığı $(7,8)$, menopoza yönelik negatif tutumların cinsel fonksiyonları olumsuz etkilediği ve depresif davranışlarla ilişkili olduğu belirtilmektedir (9). Ghazanfarpour ve ark. (10) menopoza karşı olumsuz tutuma sahip olan kadınlarda, sıcak basması, gece terlemesi, uykusuzluk, memnuniyetsizlik, baş ve boyun ağrısı, sinirlilik, hafıza kaybı, fiziksel gücün azalması, depresyon duyguları gibi menopozal yakınmaların daha fazla olduğunu belirlemiştir. Menopoz döneminde yaşanan sıkıntılar kadının bu döneme uyumunu zorlaştırmaktadır. Kadınların menopoz döneminde meydana gelen fiziksel, zihinsel, sosyal ve psikolojik değişiklikleri bilmesi, bu değişikliklerle başa çıkmasına yardımcı olmaktadır $(11,12)$. Bu nedenle, kadınların menopoz döneminde sağlığının korunması ve geliştirilmesi için menopoza yönelik bilgi, düşünce ve tutumlarının olumlu yönde değiştirilmesi ve geliştirilmesi gerekmektedir. Bireylerin menopoza yönelik bilgi ve tutumlarının olumlu yönde geliştirilmesinde sağlık eğitimi, düşük maliyetli ve etkili bir yöntemdir. Yapılan bir çalışma bilişsel, duygusal ve sosyal düzeylerde bilgi aktarımı ve deneyim paylaşımı içeren bir eğitim programının, kadınların menopoza karşı tutumlarını olumlu yönde geliştirebileceğini ve yaşam kalitesini arttırabileceği belirtilmektedir (13). Menopoza ilişkin olumlu tutum geliştirilmesinde ve kadınların bu dönemde desteklenmesinde sağlik profesyonelleri etkin rol oynamaktadır. Sağlık profesyonelleri tarafindan verilen planlı sağlık eğitiminin menopoza yönelik olumlu tutumu arttırmada etkili olduğu düşünülmektedir. $\mathrm{Bu}$ çalışmada sağlık eğitiminin kadınların menopoza yönelik tutumlarına etkisi araştırılmıştır.

Araştırma, menopoz dönemine yönelik uygulanan eğitim programının kadınların menopoza yönelik tutumlarına etkisini belirlemek amacıyla yürütüldü.

\section{Materyal-Metot}

Araştırmanın Türü: Araştırma ön test test-son test modeline dayalı yarı deneysel bir çalışma olarak yapıldı.

Araştırmanın Evren ve Örneklemi: Araştırma Altındağ Belediyesi Kültür ve Sosyal İşler Müdürlüğüne bağlı Kadın Eğitim Kültür Merkezinde yürütüldü. $\mathrm{Bu}$ merkezlerde 23.11.2017-23.05.2018 tarihleri arasında "Menopoz Okulu" adı ile düzenlenen eğitim programına kayıt yaptıran ve eğitimi tamamlayıp katılım belgesi almaya hak kazanan tüm kadınlar araştırma kapsamına alındı. İlgili tarihler arasında 20 kişilik 5 eğitim düzenlendi. Bu eğitimlere 100 kadın kayıt yaptırdı. Bu kadınlardan 62'si eğitimi (5 hafta süren) eksiksiz tamamlayarak katılım belgesi almaya hak kazand.
Bu nedenle araştırma 62 kadınla tamamlandı. Araştımanın gücü G-power 3.1 kullanılarak hesaplandı ve 0,98 olarak bulundu.

Araştırmanın Uygulanması: Katılımcılara "Menopoz Okulu" adı altında bir eğitim programı düzenlendi. Menopoz Okulu kapsamında, kadınların menopoz dönemine ait olumsuz tutum ve algılarının değiştirilmesi, bilgi eksiklikleri giderilerek bu sürece uyumlarının sağlanması amaçlandı. Eğitimler araştırmacılar tarafından verildi.

$\mathrm{Bu}$ çalışmada eğitimler başlamadan önce belediye çalışanları aracılığıyla kadınlara menopoz eğitimi hakkında bilgilendirme yapıldı. Her grupta eğitim başlamadan üç hafta öncesinde eğitime kayıtlar alındı. Kayıtlar sırasında kadınlara, araştırmanın konusu, amacı, nasıl yürütüleceği, neler yapılacağına ilişkin bilgilendirme yapıldı ve aydınlatılmış onamları alındıktan sonra kadınlar çalışmaya dahil edildi. Araştırmanın akış şeması Şekil 1'de verildi.

Menopoz Okuluna Kayıt Yaptıran Kadınlar

\begin{tabular}{|c|c|c|} 
Ön Test (n=100) & $\begin{array}{c}\text { Menopoz Okulu } \\
\text { Eğitimi }\end{array}$ & Son Test (n=62) \\
\hline
\end{tabular}

Eğitim Haftalar $\quad \begin{array}{lllll}1 & 2 & 3 & 4 & 5\end{array}$

Şekil 1. Araştırmanın akış şeması

Araştırma 23.11.2017-23.05.2018 tarihleri arasında yürütüldü. Eğitimler 20 kişilik gruplar halinde yapıldı. Toplam 100 kişiye bu eğitimlere kayıt yaptırd1. Grup eğitimleri haftada bir gün (her hafta aynı gün ve saatler arasında) olmak üzere 5 hafta süresince verildi. Eğitimler kapalı grup olarak yürütüldü. Eğitime ilk haftadan sonra yeni kişi kabul edilmedi. Eğitimler Kadın Eğitim Kültür Merkezinde yer alan eğitim salonunda yapıldı. Oda düzeni U düzeni şeklinde ayarlandı. Eğitimin ilk haftasında eğitimin amacı, süresi, kurallarına ilișkin katılımcılar bilgilendirildi. Katılımcıların kendilerini tanıtması ve beklentilerini ifade etmeleri sağlandi. Tanıtıcı bilgiler formu dolduruldu ve kadınların menopoza yönelik tutumları değerlendirildi. Programda yer alan konular 5 hafta sürecince anlatıldı (Tablo 1). Her hafta eğitim sonunda isteyen kişilere bireysel danışmanlık verildi. Beş hafta boyunca eğitime tam katılan 62 kadına katılım belgesi verildi. Son eğitim bitiminden iki ay sonra katılım belgesi almaya hak kazanan katılımcıların menopoza yönelik tutumları tekrar değerlendirildi. Eğitim öncesinde toplanan veriler ile eğitim sonunda toplanan veriler karşılaştırıldı.

Veri Toplama Araçları ve Özellikleri: Araştırma verileri, Tanıtıcı Bilgiler Formu ve Menopoza İlişkin Tutum Ölçeği kullanilarak toplandi.

Tanitıcı Bilgiler Formu; Araştırmacılar tarafından ilgili literatürden (5-13) yararlanılarak hazırlanan form toplam 26 sorudan oluşmaktadır. Bu form yaş, medeni durum, çalışma durumu, aile tipi, menopoza girme durumu, menopoza girme şekli ve zamanı, menopoz hakkında bilgi alma durumu ile ilgili soruları içermektedir.

Menopoza Illişkin Tutum Ölçeği (MITÖ); farklı yaş 
gruplarındaki kadınların menopoz yaşantısı ve sonrasına yönelik tutumlarını ölçmek amacıyla Uçanok (14) tarafından 1994 yılında geliştirilmiştir. Ölçekte 2 adet olumlu, 18 adet olumsuz olmak üzere toplam 20 ifade bulunmaktadır. Olumlu ifadeler için, "Kesinlikle katılmıyorum" yanıtına 0 puan, "Katılmiyorum"yanitına 1 puan, "Kararsızım" yanıtına 2 puan, "Katılıyorum" yanıtına 3 puan ve "Kesinlikle katıliyorum" yanıtına 4 puan verilmektedir. Olumsuz ifadelerde ise bu puanlama ters yönde yapılmaktadır. Ölçekten alınabilecek en düşük puan 0 , en yüksek puan ise 80 'dir. Ortalama puan olan 40 üzerinde alınan puanlar yükseldikçe tutumun daha olumlu olduğu kabul edilmektedir. Ölçeğin tümü için Cronbach Alfa kat sayısı 0,86 olarak bulunmuştur (14). Bu araştırmada Cronbach alfa değeri ilk ölçüm için 0,77 ikinci ölçüm için 0,81 olarak bulundu.

Tablo 1. Eğitim programı

\begin{tabular}{|c|c|}
\hline & PROGRAM İÇERİĞİ \\
\hline \multirow{3}{*}{ 1. Hafta } & Kadın iç ve dış üreme organları, üreme fizyolojisi \\
\hline & Menopoz dönemi ve menopoz yaşını etkileyen faktörler, \\
\hline & Menopoz döneminin evreleri ve özellikleri \\
\hline \multirow{6}{*}{ 2. Hafta } & Menopoz dönemi belirtileri \\
\hline & Fiziksel belirtiler \\
\hline & Psiko-sosyal belirtiler \\
\hline & $\begin{array}{l}\text { Menopoz döneminde sık görülen rahatsılılılar ve baş } \\
\text { etme yöntemleri }\end{array}$ \\
\hline & Menopoz döneminde kronik hastalıkların seyri \\
\hline & Menopoz döneminde tehlike belirtileri \\
\hline \multirow{6}{*}{ 3. Hafta } & Menopozda sağlıklı yaşam davranışları \\
\hline & Menopoz döneminde öz bakım \\
\hline & Menopoz döneminde beslenme \\
\hline & Menopoz döneminde egzersiz \\
\hline & Aile planlaması ve cinsellik \\
\hline & Menopoz ve yaşam kalitesi \\
\hline \multirow[t]{2}{*}{ 4. Hafta } & $\begin{array}{l}\text { Menopoz döneminde koruyucu sağlik uygulamaları, } \\
\text { takip ve tedavi }\end{array}$ \\
\hline & Menopoz ve HRT \\
\hline \multirow{3}{*}{ 5. Hafta } & Kadın Sağlığı için önemli tarama testleri \\
\hline & Jinekolojik Kanserler \\
\hline & Osteoporoz \\
\hline
\end{tabular}

Verilerin Değerlendirilmesi: Araştırma verileri SPSS (20.0) for Windows Software Paket Programı kullanılarak değerlendirilmiştir. Verilerin normal dağılım gösterip göstermediğinin değerlendirilmesinde One-Sample Kolmogorov-Simirnov testi kullanıldı. Bu sonuca göre verilerin analizinde parametrik testler kullanıldı. Demografik yapıyı belirlemek üzere sayı ve yüzdeyi içeren tanımlayıcı testler, eğitim öncesi ve sonrası farklılı̆̆ ölçmek için eşleştirilmiş iki grup arasındaki farkların testi (Paired-Samples “t” testi) ve Mc-Nemar testi, ikili grupların karşılaştırılmasında t testi, üçten fazla grupların karşılaştırılmasında ise tek yönlü varyans analizi (ANOVA) kullanıldı. Önemlilik düzeyi $\mathrm{p}<0,05$ olarak alınd.
Araştırmanın Etik Boyutu: Araştırmanın yapılabilmesi için ilgili kurumdan yazılı izin alındı. Araştırmanın uygulanması için Ankara Üniversitesi Etik Kurulu'ndan onay alındı (06.11.2017/286). Araştırmaya katılmayı kabul eden kadınlardan yazılı bilgilendirilmiş onam alındı.

\section{Bulgular}

Araştırmaya katılan kadınların, \%69,4'ü ilkokul mezunu, $\% 82,3$ 'ü çekirdek aile yapısına sahip, \%66,1'inin en uzun yaşadığı yerleşim birimi ildir. Kadınların \%95,7'si çalışmamakta ve $\% 67,7$ 'si gelirini orta düzey olarak

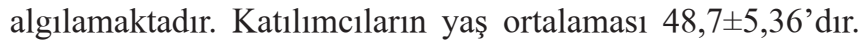
Katılımcıların \%98,4'si evli olup \%96,8'si çocuk sahibidir. Katılımcıların \%6,5'i sigara içtiğini, \%46,8'inin ise sürekli kullandığı bir ilaç olduğunu belirtmiştir. Kadınların \%74,2'si menopoza girmiştir (bir yıl boyunca menstruasyon olmayan kadınlar menopoza girmiş kabul edilmiştir). Kadınların \%84,8'i doğal yolla, \%15,2'si cerrahi yolla menopoza girmiştir.

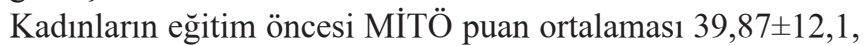
eğitim sonrası MİTÖ puan ortalamas1 ise 52,32 $\pm 10,33$ olup, eğitim öncesi ve eğitim sonrası MíTÖ puan ortalamaları arasında istatistiksel olarak önemli farklılık bulunmuştur $(\mathrm{p}<0,001)$ (Tablo 2).

Tablo 2. Eğitim öncesi ve sonrası menopoza ilişkin tutum ölçeği puan ortalamalarının dağılımı

\begin{tabular}{lccc}
\hline Ölçek Puanı & n & $\begin{array}{c}\text { Puan } \\
\text { Ortalaması }\end{array}$ & $\begin{array}{c}\text { İstatistiksel } \\
\text { Analiz }\end{array}$ \\
\hline İlk Ölçüm (Ön Test) & 62 & $39,87+12,1$ & $\mathbf{p}<\mathbf{0 , 0 0 1}$ \\
\hline Son Ölçüm (Son Test) & 62 & $52,32 \pm 10,33$ & $\mathbf{t = - 7 , 2 3 3}$ \\
\hline
\end{tabular}

Eğitim öncesinde kadınların \%51,6's1 menopoza yönelik olumlu tutuma sahipken, eğitim sonrasında bu oran \%85,5'e yükselmiş olup iki ölçüm arasındaki fark istatistik açıdan önemlidir $(\mathrm{p}<0,001)$ (Tablo 3, Grafik 1).

Tablo 3. Kadınların menopoza ilişkin tutumlarının eğitim öncesi ve sonrası dağılımı

\begin{tabular}{lccc}
\hline & $\begin{array}{c}\text { Olumlu } \\
\text { Tutum } \\
\mathrm{n}(\%\end{array}$ & $\begin{array}{c}\text { Olumsuz } \\
\text { tutum } \\
\mathrm{n}(\%)\end{array}$ & Analiz* $^{*}$ \\
\hline Eğitim Öncesi & $32(51,6)$ & $30(48,4)$ & $\mathbf{x}=\mathbf{1 4 , 8 1 5}$ \\
\hline Eğitim Sonrası & $53(85,5)$ & $9(14,5)$ & $\mathbf{p}<\mathbf{0 , 0 0 1}$ \\
\hline
\end{tabular}

*McNemar Testi yapılmıştır.

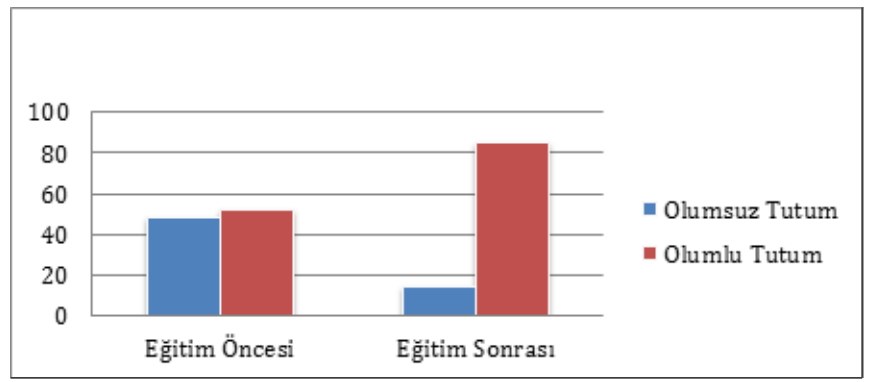

Grafik 1. Kadınların menopoza ilişkin tutumlarının eğitim öncesi ve sonrası dağılım grafiği 
Kadınların en uzun yaşadığı yerleşim birimine göre eğitim öncesi MİTÖ puan ortalamaları arasında istatistik olarak önemli bir farklılık vardır $(\mathrm{p}<0,05)$. Kadınların aile tipi, çalışma durumu, eğitim durumu, ekonomik durumu, çocuk sahibi olma durumu, sigara içme, sürekli ilaç kullanma, menopoza girme durumu, menopoza girme şekline göre eğitim öncesi MİTÖ puan ortalamaları arasında fark yoktur $(\mathrm{p}>0,05)$.

\section{Tartışma}

Menopoz dönemi, kadın yaşamındaki önemli dönemlerden birisi olup, bu dönemde fiziksel, duygusal, sosyal ve psikolojik bazı değişiklikler yaşanabilmektedir. Bu nedenle kadınların menopozal dönemde sağlik profesyonelleri tarafindan desteklenmesi gerekmektedir. Kadınların menopoza yönelik tutumları, bu döneme yönelik uyumlarını ve semptomlarla başetmelerini etkilemektedir. Tümer ve Kartal (7) tarafından yapılan bir çalışmada olumlu menopozal tutum içinde olan kadınların menopozal yakınmalarının hafif düzeyde olduğu ve daha az menopozal semptom yaşadığı belirlenmiştir. Başka bir çalışmada menopozal tutumların cinsel yaşam kalitesi üzerine etkisinin olduğu belirlenmiş ve kadınların menopozal tutumlarının daha olumlu olmasiyla birlikte cinsel yaşam kalitelerinin artabileceği belirtilmiştir (15). Bu çalışmada eğitim öncesinde kadınların neredeyse yarısının olumsuz tutuma sahip olduğu ve MITÖ puan ortalamasının 39,87+12,1 olduğu saptanmıştır. Çalışmamıza benzer şekilde Erbaş ve Demirel'in çalışmasında (15) menopozal tutum ölçek puan ortalaması 37,9+9,8 olarak belirlenmiştir. $\mathrm{Bu}$ sonuçlar ülkemizde kadınların menopoza yönelik tutumlarının olumsuz olduğunu göstermektedir. Ayrıca bu durum kadınların menopoza yönelik tutumlarının olumlu yönde geliştirilmesi gerekliliğini ortaya koymasının yanı sıra, menopozal dönemdeki kadınların sağlık bakım hizmetleri planlanırken kadınların menopoza yönelik tutumlarının da değerlendirilmesi gerektiğinin önemini göstermektedir.

Çalışmamızda menopoza yönelik verilen planlı eğitimin kadınların menopoza yönelik tutumlarını olumlu yönde geliştirmede etkili olduğu ortaya konmuştur. Kwak ve ark. (12) yaptıkları çalışmada menopoz bilgisinin, menopozu yönetme yeteneğini geliştirmede çok önemli olduğunu belirlemiş ve kadınlarının bilgi düzeyini arttırmak için uygun eğitim programlarının geliştirilmesi gerektiğini ortaya koymuştur. Yapılan bir çalışmada yapılandırılmış öğretim programının kadınlara menopoz semptomları ve yönetimi ile ilgili bilgi düzeyini artırmada etkili bir strateji olduğu saptanmıştır (14). Benzer şekilde Hasan ve ark. (17) eğitim öncesinde kadınların \%23,3'ünün menopoza yönelik pozitif tutuma sahip olduğunu, eğitim sonrası bu oranın \%46,7'ye yükseldiğini ve aradaki farkın istatistiksel olarak önemli olduğunu belirlemiştir (17). Taherpour ve ark. (18) 100 kadınla yaptıkları çalışmada kadınların \%59'unun eğitim öncesi menopoza ilişkin tutumlarının olumlu olduğunu, eğitim bittikten iki ay sonra yapılan ölçümde bu oranın \%80'ne yükseldiğini belirtmiştir. Orabi tarafından yapılan çalışmada (19) menopoza yönelik yapılan sağlık eğitiminin kadınların olumlu tutumlarını \%6,3'den \%90'na çıkardığı saptanmıştır. Literatürde menopoza ilişkin bilgi alma ile tutum arasında bir ilişki olmadığını belirleyen az sayıda çalışma da mevcuttur ( 9 , 20). Menopoz dönemi hakkında kadınların bilgi düzeylerini artırmak menopoza uyumlarını kolaylaştırmakta ve menopoz semptomlarıyla daha iyi başetmelerini sağlamaktadır. Bu nedenle kadınlara verilmesi gereken menopoz dönemi sağlık bakım hizmetleri içinde bilgilendirme ve danışmanlık hizmetlerinin yer alması önemlidir.

\section{Sonuç}

$\mathrm{Bu}$ çalışmada menopozla ilgili verilen planlı sağlık eğitiminin, kadınların menopoza ilişkin tutumlarını olumlu yönde geliştirdiği belirlenmiştir. Çalışma sonuçlarına göre menopozal dönemdeki kadınlara yönelik planlı sağlık eğitimi programlarının sağlık hizmetleri sistemine entegre edilmesi önerilmiştir. Menopozal dönemdeki kadınlara hizmet veren sağlık profesyonellerinin, kadınların menopozal semptomlarla başetmelerini kolaylaştırmak için yeterli bilgilendirme ve danışmanlık yapılması gerekliliği konusunda farkındalıklarının arttırılması da büyük önem taşımaktadır.

\section{Kaynaklar}

1. WHO Scientific Group. apps.who.int [Internet]. Geneva: Research on themenopause in the 1990s. WHO Technical Report Series 866, [1996]. Available from: http://apps.who. int/iris/bitstream/handle/10665/41841/WHO_TRS_866. pdf? sequence $=1 \&$ isAllowed $=\mathrm{y}$

2. Li S, Ho S, Sham A. Relationship between menopause status, attitude toward menopause, and quality of life in Chinese midlife women in Hong Kong. Menopause 2016; 23(1): 67-73. doi:10.1097/GME.0000000000000566

3. Pınar ŞE, Yıldırım G, Duran Ö, Cesur B. Kadına özgü bir sorun: Menopozda ruh sağlığı. Journal of Human Sciences 2015; 12(2): 787-98. doi:10.14687/ijhs.v12i2.2971

4. Erbil N. Attitudes towards menopause and depression, body image of women during menopause. Alexandria Journal of Medicine 2018; 54(39): 241-6. doi.org/10.1016/j. ajme.2017.05.012

5. Hunter M, Rendall M. Bio-psycho-socio-cultural perspectives on menopause. Best Pract Res Clin Obstet Gynaecol 2007; 21: 261-74. doi:10.1016/j. bpobgyn.2006.11.001

6. Fışkıı G, Hotun-Şahin N, Kaya İG. Menopozal dönemdeki kadınların bu yaşam dönemine ilişkin bakış açılarının kalitatif analizi. JAREN 2017; 3(3) :122-8. doi: 10.5222/ jaren.2017.122

7. Tümer A, Kartal A. Kadınların menopoza ilişkin tutumları ile menopozal yakınmaları arasındaki ilişki. Pam Tıp Derg 2018; 11(3); 337-46

8. Ayersa B, Forshaw M, Hunter MS. The impact of attitudes towards the menopause on women's symptom experience: A systematic review. Maturitas 2010; 64(1): 28-36. doi:10.1016/j.maturitas.2009.10.016

9. Marván ML, Espinosa-Hernández G, Martínez-Garduño MD, Jasso K. Attitudes toward menopause, sexual function and depressive symptoms in Mexican women. J Psychosom Obstet Gynaecol 2018; 39(2): 121-7. doi:10.1080/016748 2X.2017.1308350

10. Ghazanfarpour M, Kaviani M, Abdolahian S, Bonakchi 
H, Najmabadi K, Naghavi M, et al. The relationship between women's attitude towards menopause and menopausal symptoms among postmenopausal women. Gynecol Endocrinol 2015; 31: 860-5 doi:10.3109/09513590.2015.10 56138

11. Noroozi E, Dolatabadi NK, Eslami AA, Hassanzadeh A, Davari S. Knowledge and attitude toward menopause phenomenon among women aged 40-45 years. J Educ Health Promot 2013; 2: 25.doi:10.4103/2277-9531.112701

12. Kwak EK, Park HS, Kang NM. Menopause knowledge, attitude, symptom and management among midlife employed women. J Menopausal Med 2014; 20(3): 118-25. doi:10.6118/ jmm.2014.20.3.118

13. Rotem M, Kushnir T, Levine R, Ehrenfeld M, A Psychoeducational program for improving women's attitudes and coping with menopause symptoms. JOGNN 2005; 34(2): 233-40. doi:10.1177/0884217504274417

14. Uçanok Z, Bayraktar R. Farklı yaş gruplarındaki kadınlarda menopoza ilişkin belirtilerin, tutumların ve yaşama bakış açısının incelenmesi. 3P Dergisi 1996; 4: 11-20.

15. Erbaş N, Demirel G (2017). Klimakterikdönemdeki kadınların menopoza ilişkin yakınmalarının ve menopozal tutumlarının cinsel yaşam kalitesi üzerine etkisinin değerlendirilmesi. ACU Sağlık Bil Derg 2017; (4): 220-225. 16. Patel V, Koshy S, Ravindra HN. Effectiveness of structured teaching programme on knowledge regarding menopausal symptoms and its management among women. IOSR J Nurs Health Sci 2014; 3: 22-6.

17. Hasan PAB, Abbasi Z. Effect of education on middleaged women's knowledge and attitude towards menopause in Mashhad. J Birjand Univ Med Sci 2006; 13(2): 9-15.

18. Taherpour M, Sefidi F, Afsharinia S, Hamissi JH. Menopause knowledge and attitude among Iranian women. J Med Life 2015; 8(SpecIss 2): 72-6.

19. Orabi EE. Effect of health education intervention on knowledge, and attitude regarding menopausal period among premenopausal female employees. Effect of Health Eduction Intervention on Knowledge 2017; 35(3): 71-84.

20. Avis NE, Mc Kinlay SM. A longitudinal analysis of women's attitudes toward the menopause: results from the Massachusetts women's health study. Maturitas 1991; 13(1): $65-79$. 